\title{
The Elist Drain Retainer: A New Adherent Drain Retainer with Antibacterial Properties
}

\author{
James J. Elist ${ }^{1 *}$, Gottfried Lemperle², Vaheh Shirvanian' ${ }^{1}$, Seyed Alireza Hosseini ${ }^{1}$ \\ ${ }^{1}$ Urologist 8500 Wilshire Blvd., Suite 707, Beverly Hills, CA, USA \\ ${ }^{2}$ Division of Plastic Surgery, University of California, San Diego, CA, USA \\ Email: ^drelist@gmail.com, Lemperle8@aol.com, vaheh_sh79@hotmail.com, alirezacrow@gmail.com
}

How to cite this paper: Elist, J.J., Lemperle, G., Shirvanian, V. and Hosseini, S.A. (2016) The Elist Drain Retainer: A New Adherent Drain Retainer with Antibacterial Properties. Open Journal of Urology, 6, 165-172. http://dx.doi.org/10.4236/oju.2016.611027

Received: August 23, 2016

Accepted: November 14, 2016

Published: November 17, 2016

Copyright $\odot 2016$ by authors and Scientific Research Publishing Inc. This work is licensed under the Creative Commons Attribution International License (CC BY 4.0).

http://creativecommons.org/licenses/by/4.0/

\begin{abstract}
Background: Surgical drains are used in at least half of all surgical operations worldwide. The gold standard for the fixation of drains to the skin is currently the "Roman garter" (RG) technique, which involves knotting a suture around the drain. Its disadvantages include the time to perform the technique, possible loosening and accidental removal, and bacterial infection with biofilm formation if left in place for weeks. Methods: The Elist Drain Retainer (EDR) has been developed, and it consists of a short plastic tube bent to $90^{\circ}$ with a side slit for the drain, fixed to a mounting patch with adhesive and an antiseptic. Results: In a clinical trial comparing 25 drain attachments with the RG versus 25 drain attachments with the new EDR, the former took an average of five minutes and the EDR took an average of one minute to place. Loosening occurred in five (20\%) drains and accidental removal occurred in four $(16 \%)$ for the RG group versus no incidences of loosening or accidental removal in the EDR group. Self-removal of the EDR was possible for seven (28\%) patients. Conclusion: The EDR demonstrated a clear advantage over the RG in all tested parameters. The lack of instruments and the possibility of self-removal of the EDR when a drain is needed are particularly advantageous features.
\end{abstract}

\section{Keywords}

Elist Drain Retainer, Roman Garter, Drain, Surgical Drain

\section{Introduction}

Many surgical and orthopedic procedures worldwide use surgical drains to prevent and remove excess fluid collection, minimize postsurgical complications, and allow the cav- 
ity to collapse and heal [1]. Active, closed-suction drains use low negative vacuum pressure to remove excess fluid and air collection from inside a wound cavity [2]. These surgical drains usually consist of a collecting tube and a collapsible or non-collapsible vacuum container.

The drain tube is inserted through the skin using an Alene needle and a separate hole to prevent incision-site complications [3]. To avoid retrograde drain and wound infection, a drain should not be pulled through the skin by retrograde insertion of a long clamp through a previous skin incision.

Appropriate fixation is required at the insertion site to prevent tube slippage into the wound cavity or unintended premature drain removal [4]. Various techniques and materials such as sutures, pins, adhesives, and clips are available for drain fixation [5], with the most commonly used method currently being the "Roman garter" (RG) technique using silk sutures (Figure 1(a)) [6]. This method uses two silk sutures to fix a drain to the patient's skin and relies on the friction created between the suture and the rubbery drain material. Retainer function with RG technique is diminished when the sutures become wet or loose and lose friction [7].

The Elist Drain Retainer (EDR) has been developed for suture-less drain fixation with additional antibacterial properties. In a prospective randomized controlled clinical study, the possible advantages of the EDR were investigated regarding efficacy, functionality, patient comfort, and cost in direct comparison to the most commonly used RG technique for drain fixation.

\section{Materials and Methods}

\subsection{The Elist Drain Retainer}

A drain is a flexible tube inserted through a narrow opening into a body cavity for the removal of fluid (Figure 1(b)). By adjusting the drain's structure and composition, it can be used for a variety of applications and medical fields such as urology, gastroenterology, and pulmonology. The EDR comes in two different sizes that will hold and lock drains and catheters sized 14-19F and 20-28F.

The EDR comprises of a catheter retainer and hollow conduit (Figure 1(c)) as well as a mounting patch that firmly affixes the base of the drain unit to the body surface (Figure 1(d)). Through the base of the drain unit, the conduit guides the catheter into the body cavity from which fluids are to be evacuated. The glue is impregnated with an antibacterial chlorhexidine gluconate solution, which may prevent retrograde bacterial growth and biofilm formation along the catheter or drain. The medial bend in the proximal end of the conduit guides the catheter and helps prevent inadvertent removal or adjustment. The mounting patch not only secures the drain to the body wall but also keeps the entry site clean and free from exposure to bacteria and other contaminants (Figures 2(a)-(d)).

The EDR is patented [US patent 8,652,107. February 18, 2014.], and developed at Solutions Matter, LLC (San Diego, CA, USA) but not yet marketed. 


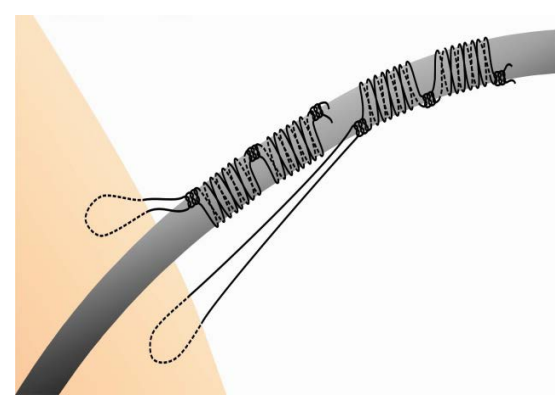

(a)

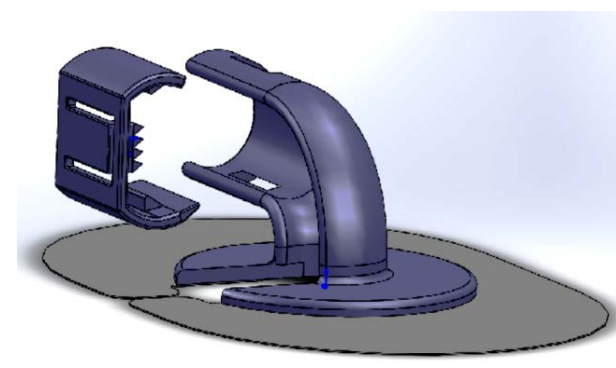

(c)

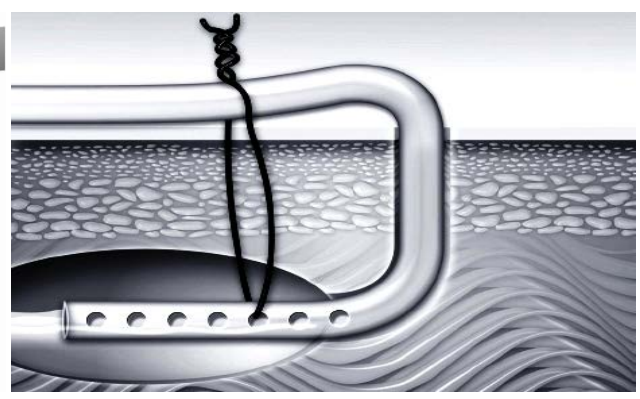

(b)

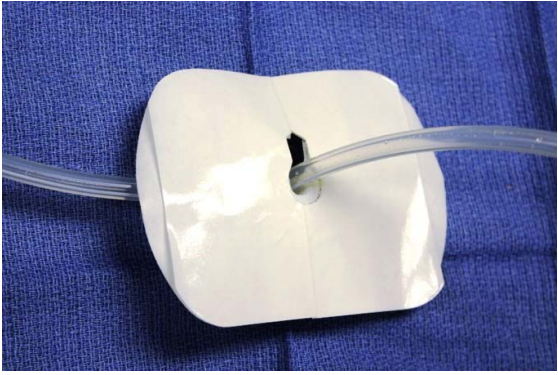

(d)

Figure 1. (a) The "Roman garter" technique is still the gold standard for fixing drains [16]. In our test series, the fixation took an average of five minutes. (b) Many tricks have been tried and published to prevent drain slipping [7]; none are used worldwide in operating rooms. (c) The Elist Drain Retainer consists of a rectangular hollow conduit that absorbs half the force of an eventual pull on the drain. (d) The bottom consists of a strong mounting patch with a non-allergenic adhesive and a film of antibacterial chlorhexidine.

\subsection{Advantages of the Elist Drain Retainer}

- Can be attached to any exterior surface of a body.

- Prevents accidental movement of the drain or catheter.

- Prevents accidental removal or further insertion of the catheter.

- Prevents constriction of the catheter.

- Provides simplified and fast use, especially to securely engage a catheter.

- Can be removed together with the drain easily, quickly, and painlessly.

\subsection{Patients}

Fifty patients (28 male, 22 female) undergoing elective surgery were assigned to two groups ( $\mathrm{n}=25$ per group) receiving either a Jackson-Pratt drain (JP drain; Cardinal Health, Dublin, OH, USA) with traditional RG (group 1) or the EDR fixation technique (group 2). The surgical procedures performed included mastectomy $(n=4)$, breast reduction ( $n=4)$, abdominoplasty $(n=12)$, laparoscopic cholecystectomy $(n=6)$, robotic prostatectomy $(n=4)$, and penile enhancement surgery $(n=20)$. For comparison of direct outcomes, each procedure was assigned similar numbers of patients for each drain, in a randomized fashion. Risks and complications were discussed and noted in detail. Verbal and written consent for the use of the EDR was obtained from all patients in group 2 . 


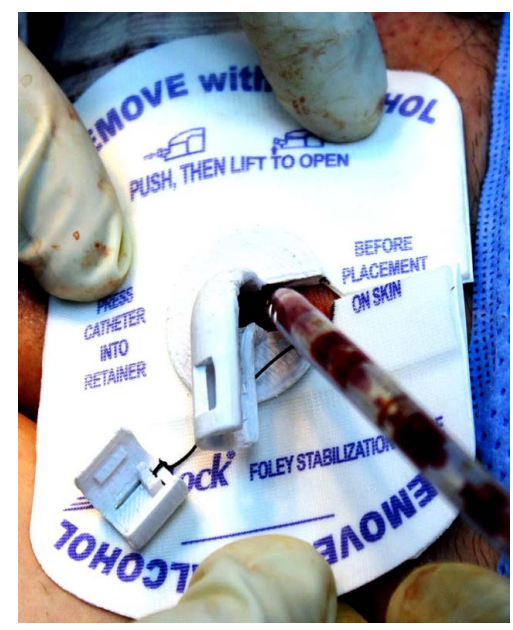

(a)

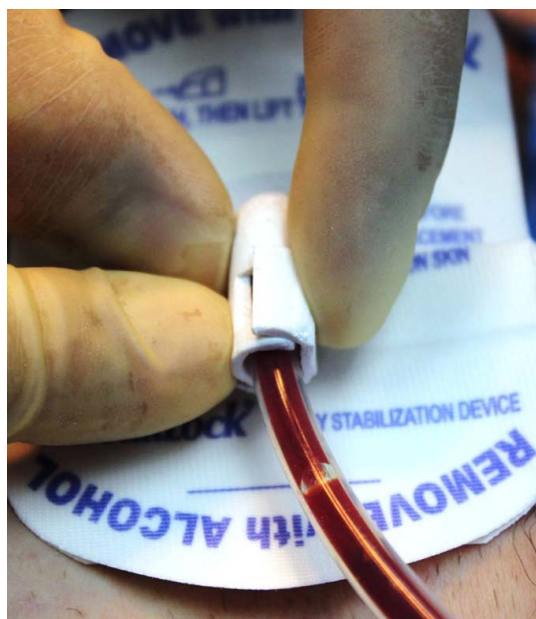

(c)

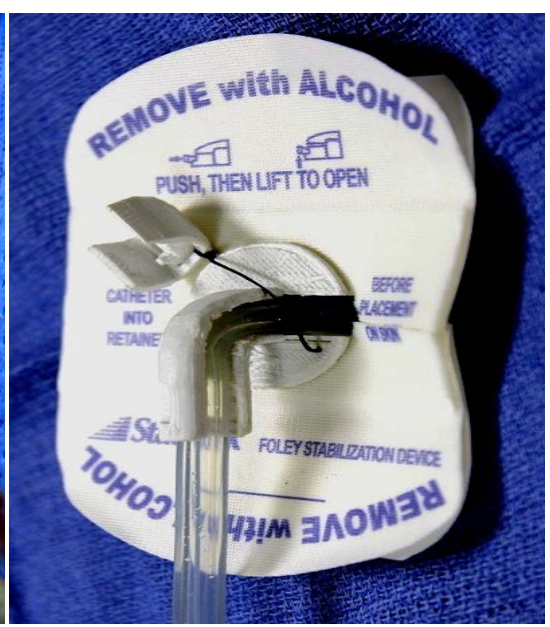

(b)

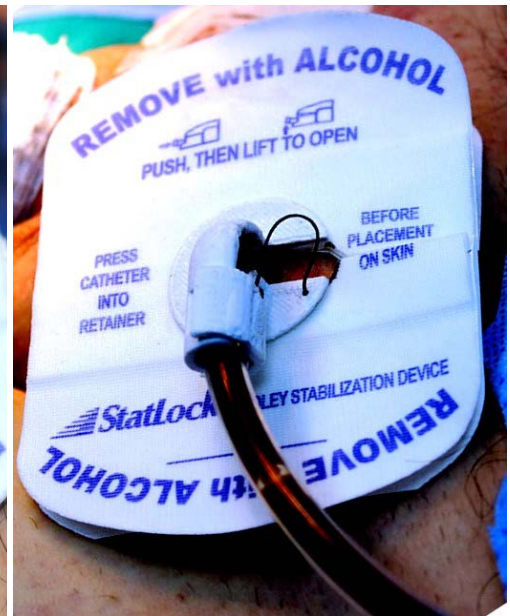

(d)

Figure 2. (a) The Elist Drain Retainer contains a toothed clip to fix the drain in the rectangular conduit. (b) The opening of the Elist Drain Retainer (EDR) is pushed across the drain; the two protecting sheets are removed, and the EDR is glued to the skin. (c) The drain is pushed into the rectangular tube. (d) The toothed clip is pushed into the drain. In our test series, fixation of the drain took an average of 54 seconds.

\subsection{Procedure}

The RG technique required the installation of an additional occlusive dressing (Tegaderm; 3 M Health Care, Neuss, Germany), whereas the EDR was applied as a one-step complete solution. Drains were removed two to six days after the procedure date, when the collected fluid dropped below $15 \mathrm{~mL}$ per 24 hours and was clear of bloody content; all drains inserted for penile enhancement surgery were removed on day three after surgery, and the wound cavity was irrigated with an antibiotic solution on days one to three post surgically per protocol using the JP drain as an irrigation port.

\subsection{Analysis}

Efficacy of the EDR versus the RG was evaluated using the following criteria: 
- Time needed for drain insertion and fixation.

- Accidental slippage or premature drain removal.

- Need for repeated drain fixation due to material failure.

- Need for reinsertion or advancement of the drain.

- Day of drain removal after surgery (duration of drain).

- Skin irritation at the drain insertion site.

- Bacterial colonization of the skin surrounding the drain orifice.

- Overall patient comfort.

The time needed for drain insertion and fixation was measured using a stopwatch, starting with the unpacking of the suture material, through suture insertion, drain fixation, and dressing application.

In the RG technique, drain advancement may require complete removal and replacement of the fixation material, and reinsertion of new suture material may become necessary to properly secure the drain. When using the EDR technique, the drain can easily be detached from the retainer, advanced, and then reinserted into the retainer without the need for a retainer replacement. The efficacy of the two techniques, considering dressing cleanliness and required dressing changes, was documented, and a swab culture from the skin immediately surrounding the incision site was taken.

\section{Results}

The insertion and securing of the drain was timed in 25 patients receiving the common RG technique and 25 patients receiving the EDR. A 19F JP drain was inserted in 45 patients, and a $15 \mathrm{~F}$ JP drain was placed in 5 patients. The average time for applying the RG was 5.1 minutes versus 54.3 seconds applying the EDR $(p<0.01)$. Removing the RG took an average of 68.7 seconds versus 44.1 seconds removing the EDR $(p>0.01)$. Self-removal of the drain after three to six days was not possible for the patients with the RG, but self-removal was achieved by 11 of 25 (44\%) EDR patients without much prolongation.

Wound closure with butterfly, clip, or suture was necessary in 20 of 25 (80\%) RG patients and in 14 of $25(56 \%)$ patients with the EDR. Accidental premature removal occurred in 4 of 25 (16\%) RG patients versus none of the EDR patients. Loosening of drains occurred in 5 of 25 (20\%) in the RG group versus 1 of 25 (4\%) in the EDR group. Reinsertion of the drain was necessary in 3 of 25 (12\%) in the RG group versus 1 of 25 (4\%) in the EDR group; EDR exchange was necessary because of a blood clot beneath the adhesive tape. Local skin irritation was reported in 8 of 25 (32\%) patients with RG and 1 of 25 (4\%) patients with EDR.

In summary, the application of the EDR took an average of one minute, one-fifth of the time of the RG, which required an average of five minutes. Removal of the EDR took two-thirds of the time that was needed for the removal of the RG, and approximately half of the patients with the EDR were able to remove the retainer by themselves (Table 1). To date, 126 patients were treated with the EDR without any clinical signs of drain or skin infection. 
Table 1. Comparison of the Roman garter technique and the Elist Drain Retainer.

\begin{tabular}{ccc}
\hline Procedures & Roman Garter $\mathrm{n}=25$ & Elist Drain Retainer $\mathrm{n}=25$ \\
\hline Time for fixation & $5.1 \mathrm{~min}$ & $54.3 \mathrm{sec}$ \\
Loosening of drains & $5(20 \%)$ & $1(4 \%)$ \\
Reinsertion of drains & $3(12 \%)$ & $1(4 \%)^{\star}$ \\
Accidental removal & $4(16 \%)$ & $0(0 \%)$ \\
Time for removal & $68.7 \mathrm{sec}$ & $44.1 \mathrm{sec}$ \\
Self-removal & $0(0 \%)$ & $7(28 \%)$ \\
Wound closure necessary & $20(80 \%)$ & $14(56 \%)$ \\
Skin irritation & $8(32 \%)$ & $1(4 \%)$ \\
\hline
\end{tabular}

${ }^{*}$ Blood clot.

\section{Discussion}

The brief task of inserting a tube, such as a central venous catheter or a chest tube, is usually followed by the longer task of ensuring that the tube will not be inadvertently pulled out. Various methods of securing tubes have been described, and yet these tubes continue to be pulled out with frustrating predictability. There have been plenty of ideas about how to avoid later slippage of the drain: stretching the silicone tube during knotting [4], making an indentation in the rubber tube before the knot is performed over the indentation [5], using strong knots from the sailing world [6], or suturing through the proximal drain hole [8]. Drains have been fixed with a suture through a proximal hole and skin [7] or with three staples fixing the drain wall to the skin [9] to prevent slipping of the drain. Another approach is to pull the catheter through a Cook disk (Cook Medical, Bloomington, IN, USA) taped with a Stomahesive wafer (ConvaTec, Skillman, NJ, USA), but two sutures are needed to fix the catheter to the nipple of the disk [10].

Drain size does not matter for drainage time, but shape matters. In an experimental setting of hemothorax in pigs, smaller chest drains (19F) drained the same volume in the same amount of time as common chest drains of $28 \mathrm{~F}$ [11]. Drainage was more rapid using flat JP drains in serous and purulent conditions, whereas round drains were more effective when debris (blood clots) was expected [12]. Low vacuum suction drains were more effective than gravity drains and had significantly lower rates of postoperative infection resulting from retrograde migration of bacteria [13]. In another study, 66 drains were placed in the presence of prosthetic material. Although nearly two-thirds of drains were colonized with bacteria, the wound infection rate was extremely low (5.6\%). Consequently, closed-suction drains may be left in place for extended periods without increasing the risk of infection [14]. A recent Cochrane meta-analysis has demonstrated again the broad effect of chlorhexidine gluconate in skin disinfection [15].

The new EDR provides a closed environment with an antibiotic patch on the skin, prevents slipping and retrograde infection, can be left for many days or weeks without dressing change, and causes little pain during removal. Its defining feature is the $90^{\circ}$ bend that diminishes possible pulling forces to at least half (Table 2). 
Table 2. Advantages and disadvantages of EDR and traditional methods.

\begin{tabular}{|c|c|c|}
\hline & Elist Drain Retainer (EDR) & Traditional "Roman Garter" \\
\hline Advantages & $\begin{array}{l}\text { - Fast application }(\sim 1 \mathrm{~min}) \\
\text { - Strong fixation } \\
\text { - No accidental removal through } 90 \text { degree } \\
\text { bending of the drain } \\
\text { - Suture-less and antibacterial } \\
\text { - Removal without instruments that can be } \\
\text { done by patient and/or non-surgeons }\end{array}$ & $\begin{array}{l}\text { - Technique well-accepted and used } \\
\text { worldwide }\end{array}$ \\
\hline Disadvantages & $\begin{array}{l}\text { - Possible skin irritation due to glue or } \\
\text { disinfectant }\end{array}$ & $\begin{array}{l}\text { - Time consuming ( } 5 \mathrm{~min}) \\
\text { - Significant costs associated with } \\
\text { application (e.g., OR time) } \\
\text { - Loosening effect and loss of friction } \\
\text { - Accidental slippage and reinsertion } \\
\text { - Risk of suture and drain infection (biofilm) }\end{array}$ \\
\hline
\end{tabular}

\section{Conclusion}

The introduction of the EDR supports surgeons, nurses, and patients. It can be applied in one-fifth of the time as the RG with higher efficiency and safety. In a larger OR with 15 operations, one hour OR-time could be saved per day. The EDR provides ease of use because it can be removed without needle holders, sutures, and sterile gowns. In addition to time savings of four minutes per fixation, a great advantage of the EDR is the possibility for self-removal by the patient. The addition of antiseptic chlorhexidine prevents wound infection and skin irritation.

\section{References}

[1] Partridge, R. and Sabharwal, A. (2013) Drains and Drain Fixation Techniques. In: Carachi, S., Agarwala, S. and Bradnock, T.J., Eds., Basic Techniques in Pediatric Surgery, SpringerVerlag, Berlin-Heidelberg, Chapter 31. http://dx.doi.org/10.1007/978-3-642-20641-2_31

[2] Durai, R., Mownah, A. and Ng, P.C. (2009) Use of Drains in Surgery: A Review. Journal of Perioperative Practice, 19, 180-186.

[3] He, X.D., Guo, Z.H., Tian, J.H., Yang, K.H. and Xie, X.D. (2011) Whether Drainage Should Be Used after Surgery for Breast Cancer? A Systematic Review of Randomized Controlled Trials. Medical Oncology, 28, S22-S30. http://dx.doi.org/10.1007/s12032-010-9673-2

[4] Bar-Maor, J.A. (1994) A Simple Technique for Anchoring Tubes to the Skin. Journal of Trauma, 36, 112. http://dx.doi.org/10.1097/00005373-199401000-00018

[5] Frank, M. (1983) A Simple Technique for Securing Tubes. Annals of Emergency Medicine, 12, 25-27. http://dx.doi.org/10.1016/S0196-0644(83)80129-2

[6] Hormbrey, E., Pandya, A. and Humzah, D. (2000) Drain Fixation Made Foolproof. Annals of the Royal College of Surgeons of England, 82, 290-292.

[7] Judd, O. and Gaskin, J. (2011) A simple, cosmetically superior method of securing a post-surgical drain in facial surgery. Annals of the Royal College of Surgeons of England, 93, 171. http://dx.doi.org/10.1308/rcsann.2011.93.2.171a

[8] Lim, P.V. and Jalaludin, M.A. (2000) An Alternative Method for Securing Surgical Drains in the Neck. Medical Journal of Malaysia, 55, 141-142.

[9] Ng, W.T., Yiu, M.K., Wong, M.K., Wong, Y.T., Kong, C.K. and Chan, Y.T. (1993) Use of Skin Staples for Fixation of T Tubes and Drains. Surgery, Gynecology \& Obstetrics, 117, 
93-95.

[10] Bron, K.M. (1982) The Non-Suture Skin Fixation of Drainage Catheters. American Journal of Roentgenology, 139, 404-405. http://dx.doi.org/10.2214/ajr.139.2.404

[11] Niinami, H., Tabata, M., Takeuchi, Y. and Umezu, M. (2006) Experimental Assessment of the Drainage Capacity of Small Silastic Chest Drains. Asian Cardiovascular and Thoracic Annals, 14, 223-226. http://dx.doi.org/10.1177/021849230601400311

[12] Swartz, A.L., Azuh, O., Obeid, L.V., et al. (2012) Developing an Experimental Model for Surgical Drainage Investigations: An Initial Report. American Journal of Surgery, 203, 388391. http://dx.doi.org/10.1016/j.amjsurg.2011.09.015

[13] Raves, J.J., Slifkin, M. and Diamond, D.L. (1984) A Bacteriologic Study Comparing Closed Suction and Simple Conduit Drainage. American Journal of Surgery, 148, 618-620. http://dx.doi.org/10.1016/0002-9610(84)90336-2

[14] Reiffel, A.J., Pharmer, L.A., Weinstein, A.L. and Spector, J.A. (2013) A Prospective Analysis of the Association between Indwelling Surgical Drains and Surgical Site Infection in Plastic Surgery. Annals of Plastic Surgery, 71, 561-565. http://dx.doi.org/10.1097/SAP.0b013e31824c905b

[15] Kim, H.Y., Lee, W.K., Na, S., et al. (2016) The Effects of Chlorhexidine Gluconate Bathing on Health Care-Associated Infection in Intensive Care Units: A Meta-Analysis. Journal of Critical Care, 32, 126-137. http://dx.doi.org/10.1016/j.jcrc.2015.11.011

[16] Fang, B.X.H., Lo, C.S.Y., Lam, A.C.S., Law, M.W.M. and Chu, F. (2014) Dislodgement of Percutaneous Nephrostomy and Biliary Catheters: The Importance of Catheter Anchoring Technique. European Congress of Radiology; Poster C-1948 in EPOS Electron.

\section{Submit or recommend next manuscript to SCIRP and we will provide best service for you:}

Accepting pre-submission inquiries through Email, Facebook, LinkedIn, Twitter, etc. A wide selection of journals (inclusive of 9 subjects, more than 200 journals)

Providing 24-hour high-quality service

User-friendly online submission system

Fair and swift peer-review system

Efficient typesetting and proofreading procedure

Display of the result of downloads and visits, as well as the number of cited articles

Maximum dissemination of your research work

Submit your manuscript at: http://papersubmission.scirp.org/

Or contact oju@scirp.org 